\title{
Prevalence of Overweight and Obesity in Children and Adolescents in Eastern Turkey
}

\author{
Sevil Arı Yuca1, Cahide Yılmaz², Yaşar Cesur¹, Murat Doğan1, Avni Kaya2, Murat Başaranoğlu² \\ ${ }^{1}$ Yüzüncü Yıl University, Faculty of Medicine, Pediatric Endocrinology, Van, Turkey \\ ${ }^{2}$ Yüzüncü Yıl University, Faculty of Medicine, Pediatrics, Van, Turkey
}

\section{ABSTRACT}

Objective: The aim of this study was to estimate the prevalence of overweight and obesity in school children in Eastern Turkey.

Methods: This study included 9048 school children aged 6-18 years. The subjects were classified as overweight and obese, according to the International Obesity Task Force.

Results: We found prevalence of overweight of $11.1 \%$ in the studied population. It was detected that $2.2 \%$ of the population in the study was obese; $2.1 \%$ of males and $2.3 \%$ of females. While the prevalence of obesity was extremely low before 9 ages and after 15, it reached to high values at puberty and just before pubertal period in boys. The prevalence of overweight was higher in girls and reached to peak point at pubertal ages. Generally, the prevalence of obesity and overweight was slightly higher in girls than in boys, although the boys were more obese in prepubertal ages.

Conclusion: Overweight and obesity are concerns for children and adolescents in low socio-economic status regions as well.

Key words: Obesity, child, adolescent

Conflict of interest: None declared

Received: 15.08 .2010

Accepted: 03.11.2010

\section{Introduction}

Obesity in children and adolescents is a global concern. In developed countries, the prevalence of overweight and obesity in children increased by a magnitude of two to five times in the last quarter of the twentieth century $(1,2,3,4,5)$. Not only developed countries but also developing countries are adversely affected $(6,7)$. There are numerous reports in the literature about childhood obesity and its adverse effects on health from different parts of the world $(1,7)$. Prevalence of overweight and obesity is on the increase also in Turkey, a country, which is undergoing rapid urbanization and changes in nutritional habits.

Reports on prevalence of overweight and obesity from the Eastern parts of Turkey are scarce $(8,9,10,11)$. This study was conducted to obtain data on prevalence of overweight and obesity in school children from the Eastern Anatolian region of Turkey.

\section{Methods}

This cross-sectional study was carried out between November 2006 and April 2007, and includes representative samples of 6-18 years old children and adolescents attending schools in Van, a city located in the Eastern Anatolian region of Turkey. The entire population of Van city is estimated to be 413907 . The children and adolescents aged $6-18$ years constitute $33.3 \%$ of this population.

\section{Address for Correspondence}

Sevil Arı Yuca MD, Yüzüncü Yıl University, Faculty of Medicine, Pediatric Endocrinology, Van, Turkey Phone: +90 4322164711 Gsm: +90 5335239050 E-mail: sevilyuca@yahoo.com

(c) Journal of Clinical Research in Pediatric Endocrinology, Published by Galenos Publishing. 
An informed consent form was distributed to the parents one day before the measurements. Participation was voluntary and written informed consent from both parents and children was obtained. The research was approved by the local ethics committee of the Yuzuncu Yil University, Faculty of Medicine as well as from the representative of the Ministry of Education in Van.

A total of 9048 students (4864 males and 4184 females) between the ages of 6 and 18 living in Van city participated in the study.

Measurements of body weight and height were carried out by one trained pediatrician and trained students attending the Medical School of Van Yuzuncu Yil University. Body weight was measured to the nearest $0.1 \mathrm{~kg}$ with an electronic scale (Tefal sense, France), with subjects undressed and wearing only underwear. Height was measured to the nearest $1 \mathrm{~mm}$ using a portable measuring device (Seca GMTH\&CO, 22089 Hamburg, Germany). For height measurements, the subjects had to take off their shoes and they stood erect against a vertical portable scale with their heels, buttocks, scapulae and the back of their heads touching the vertical plane. In the present study, unfortunately pubertal examination was not performed due to socio-cultural reasons.

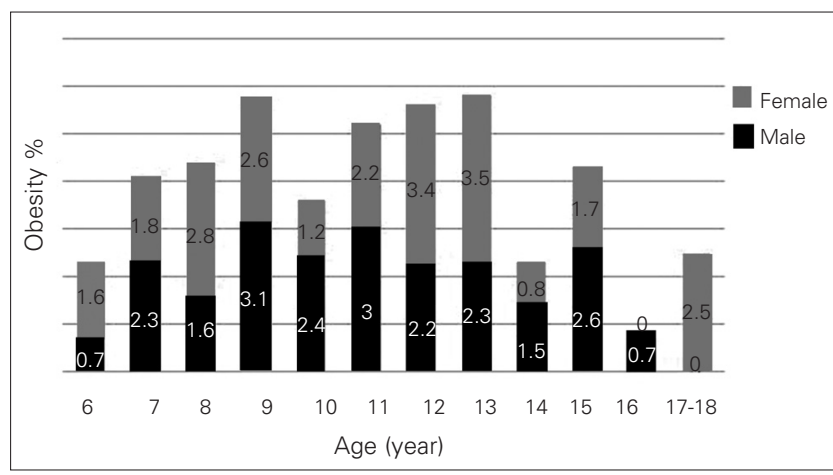

Figure 1. Percentage(\%) of obesity in 6-18 years-old children for age and gender

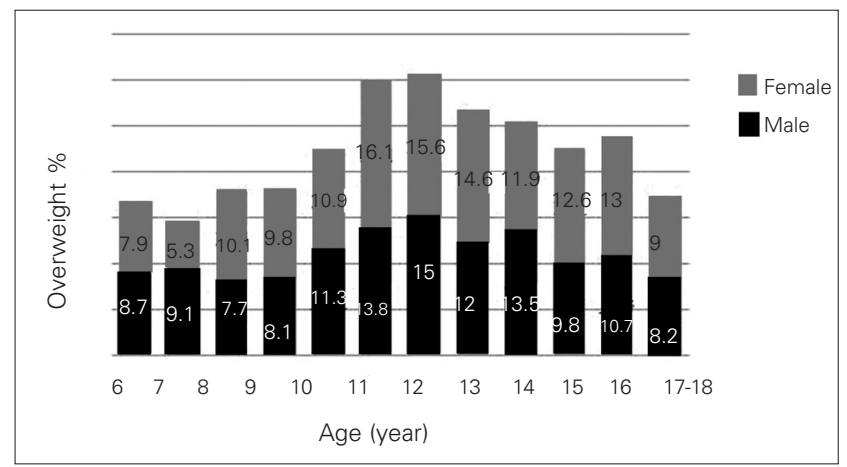

Figure 2. Percentage(\%) of overweight in 6-18 years-old children for age and gender
Body mass index (BMI) was calculated as the ratio of the body weight to the square of body height $\left[\mathrm{BMI}=\right.$ weight $(\mathrm{kg}) /$ height $\left.\left(\mathrm{m}^{2}\right)\right]$. Estimation of the prevalence of overweight and obesity was based on the cut-off points of the International Obesity Task Force (IOTF) standards (12).

Information on birth dates was obtained from the parents. If the birth date was not known precisely, these children were excluded. Age groups were defined as year \pm 6 months.

The statistical analyses were performed with SPSS 15.0 software for Windows (SPSS Inc., Chicago, IL, USA). For each survey, means and standard deviations were calculated for each sex. Mean values were compared using the Student's t test. To define overweight and obesity based on $\mathrm{BMI}$, observed and expected numbers in each category were compared using the $x^{2}$ test. Pearson's correlation analysis was used to reveal the relationships between obesity and age groups.

\section{Results}

The sample representing the age groups between 6 and 18 years consisted of 9048 subjects $(46.2 \%$ girls and $53.8 \%$ boys). The mean age was $10.3 \pm 2.8$ years $(10.2 \pm 2.8$ in girls and $10.4 \pm 2.9$ in boys). Overall prevalence figures for overweight and obesity in this group of Turkish children and adolescents according to gender are shown in Table 1. In the total group, prevalence rates of overweight and obesity were $11.2 \% \quad(n=1006)$ and $2.2 \% \quad(n=198)$, respectively. These figures were $10.9 \%$ and $2.1 \%$ in boys, and $11.4 \%$ and $2.3 \%$ in girls. The prevalence rates of overweight and obesity in girls were higher than in boys $(p=0.001)$.

Prevalence rates of overweight and obesity according to age and gender are shown in Tables 2 and 3 as well as in Figures 1 and 2 . In boys, the prevalence of overweight reached to the highest values between ages 10 and 16 years (except for a mild decrease at age 15) with a peak point at age 12 years. In girls, prevalence reached its highest point at age 11 and this high level was maintained until age 16; a decrease occurred at ages 17 and 18, similar to the finding in the boys. Prevalence of overweight was not high in preadolescent ages in either gender, and the lowest value for boys and girls was at ages 9 and 7 , respectively.

Table 1. Prevalence of overweight and obesity in boys and girls in the total sample

\begin{tabular}{llllll}
\hline & n & \multicolumn{2}{c}{ Overweight } & \multicolumn{2}{c}{ Obesity } \\
\hline & & Number & $\%$ & Number & $\%$ \\
Boys & 4864 & 528 & 10.9 & 103 & 2.1 \\
Girls & 4184 & 478 & 11.4 & 95 & 2.3 \\
\hline Total & 9048 & 1006 & 11.1 & 198 & 2.2 \\
\hline
\end{tabular}


A comparative evaluation of boys and girls for prevalence of overweight showed that prevalence was higher in boys than in girls at age groups 6,7 and 14 years. In the 12-year age group, prevalence of overweight was similar in girls and boys. Prevalence of overweight was higher in the girls in all other age groups $(p=0.001)$ (Table 2 , Figure 2).

The prevalence of obesity was extremely low in the 6 -year age group and showed a peak in the age groups
9 and 11 years. Thereafter, prevalence gradually decreased in boys, except for an increase at age 15 years. In girls, prevalence increased with age (except for ages 10 and 11); finally, it reached its highest rate in the 12-13-year age groups, similar to the pattern of prevalence of overweight (Table 3). In boys, prevalence rate was low at ages 14-16, showed an increase at ages 17-18, and decreased after age 15.

In girls, we found a positive and significant correlation between prevalence of overweight and age ( $O R=0.074 /$ $\mathrm{p}=0.001$ ).

\begin{tabular}{|c|c|c|c|c|c|c|}
\hline \multirow[t]{2}{*}{ Age group (years) } & \multicolumn{3}{|c|}{ Boys } & \multicolumn{3}{|c|}{ Girls } \\
\hline & $\begin{array}{l}\text { Total } \\
\text { group (n) }\end{array}$ & $\begin{array}{l}\text { Overweight } \\
\text { (n) }\end{array}$ & $\%$ & $\begin{array}{l}\text { Total } \\
\text { group (n) }\end{array}$ & $\begin{array}{l}\text { Overweight } \\
\text { (n) }\end{array}$ & $\%$ \\
\hline 6 & 400 & 35 & 8.7 & 427 & 34 & 7.9 \\
\hline 7 & 569 & 53 & 9.1 & 488 & 26 & 5.3 \\
\hline 8 & 502 & 39 & 7.7 & 464 & 47 & 10.1 \\
\hline 9 & 519 & 42 & 8.1 & 425 & 42 & 9.8 \\
\hline 10 & 540 & 61 & 11.3 & 430 & 47 & 10.9 \\
\hline 11 & 470 & 65 & 13.8 & 446 & 72 & 16.1 \\
\hline 12 & 538 & 81 & 15 & 493 & 77 & 15.6 \\
\hline 13 & 568 & 68 & 12 & 480 & 70 & 14.6 \\
\hline 14 & 332 & 45 & 13.5 & 235 & 28 & 11.9 \\
\hline 15 & 153 & 13 & 9.8 & 119 & 15 & 12.6 \\
\hline 16 & 140 & 15 & 10.7 & 100 & 13 & 13 \\
\hline $17-18$ & 133 & 11 & 8.2 & 78 & 7 & 9 \\
\hline Total & 4864 & 528 & 10.9 & 4184 & 478 & 11.4 \\
\hline
\end{tabular}

\begin{tabular}{|c|c|c|c|c|c|c|}
\hline \multirow[t]{2}{*}{ Age group (years) } & \multicolumn{3}{|c|}{ Boys } & \multicolumn{3}{|c|}{ Girls } \\
\hline & $\begin{array}{l}\text { Total } \\
\text { group (n) }\end{array}$ & $\begin{array}{l}\text { Obese } \\
\text { (n) }\end{array}$ & $\%$ & $\begin{array}{l}\text { Total } \\
\text { group (n) }\end{array}$ & $\begin{array}{l}\text { Obese } \\
\text { (n) }\end{array}$ & $\%$ \\
\hline 6 & 400 & 3 & 0.7 & 427 & 7 & 1.6 \\
\hline 7 & 569 & 13 & 2.3 & 488 & 9 & 1.8 \\
\hline 8 & 502 & 8 & 1.6 & 464 & 13 & 2.8 \\
\hline 9 & 591 & 16 & 3.1 & 425 & 11 & 2.6 \\
\hline 10 & 540 & 13 & 2.4 & 430 & 5 & 1.2 \\
\hline 11 & 470 & 15 & 3 & 446 & 10 & 2.2 \\
\hline 12 & 538 & 12 & 2.2 & 493 & 17 & 3.4 \\
\hline 13 & 568 & 13 & 2.3 & 480 & 17 & 3.5 \\
\hline 14 & 332 & 5 & 1.5 & 235 & 2 & 0.8 \\
\hline 15 & 153 & 4 & 2.6 & 119 & 2 & 1.7 \\
\hline 16 & 140 & 1 & 0.7 & 100 & 0 & 0 \\
\hline $17-18$ & 133 & 0 & 0 & 78 & 2 & 2.5 \\
\hline Total & 4864 & 103 & 2.1 & 4184 & 95 & 2.3 \\
\hline
\end{tabular}




\section{Discussion}

The prevalence of overweight and obesity among children and adolescents worldwide is gradually increasing $(13,14,15,16,17,18)$. Although the highest prevalence rates of childhood obesity are observed in developed countries, obesity is also increasing in developing countries $(19,20)$.

Obesity in adolescence is associated with increased morbidity in adulthood $(21,22,23,24)$. BMI is a sensitive and specific indicator of excess adiposity among children. Overweight is defined as a BMI between the $85^{\text {th }}$ and $95^{\text {th }}$ percentile for age and sex, and obesity-as a BMI greater than the $95^{\text {th }}$ percentile $(25,26,27)$. There may be differences in the BMI reference normal standards among different countries, but the IOTF standards are recommended for general use (12).

In our study, the prevalence of overweight was highest at ages 9 and 11 in boys and 12-13 in girls. The prevalence of overweight was low at ages 14-16, but increased again in the older age groups (17-18 years) in girls, whilst prevalence showed a decline after ages 16 in the boys. However, the numbers of subjects may have been too low in the older age groups. In girls, there was a positive and significant correlation between prevalence of overweight and age, but such correlation was not observed in boys.

The prevalence rates of overweight and obesity in our region (Eastern Anatolian) were lower than those previously reported from other areas in Turkey $(8,9)$. Our data show lower prevalence rates in both genders compared to the rates from regions in the Northern, Southern and Middle parts of Anatolia (in these regions, the overall prevalence of obesity was $6.1 \%, 3.6 \%, 4.1 \%$, respectively). Our results are higher than those in boys and almost equal with those in girls from Western Turkey (1.6\% in boys, $2.1 \%$ in girls) $(8,10)$.

Comparison of our data with reports from other countries has shown that prevalence of overweight and obesity in our region was lower than those reported from European countries, from US and some Asian countries $(2,5,7,13,28)$.

In conclusion, we found that the prevalence of obesity was similar in both genders, but the rates showed peaks at different ages (at 11 years in boys and 12-13 years in girls). The prevalence of overweight was higher in girls and showed three peaks (at ages 8-9 years, 11-13 years and 17-18 years). The prevalence of obesity was higher in girls, although the boys were more obese than the girls in some age groups (Figure 1). This is the first report of prevalence of obesity in the Eastern Turkey and our results indicate that overweight and obesity are concerns for children and adolescents in the Eastern Anatolia as well, particularly in adolescent girls.

\section{References}

1. Obesity: preventing and managing the global epidemic. Report of a WHO consultation. World Health Organ Technical Report Series 2000;894:1-253. [Abstract]

2. Ogden L, Carroll MD, Curtin LR, McDowell MA, Tabak CJ Flegal KM. Prevalence of overweight and obesity in the United States, 1999-2004. JAMA 2006;295:1549-1555. [Abstract] / [Full Text] / [PDF]

3. Seidell JC. Obesity: a growing problem. Acta Paediatr 1999; 88:46-50. [Abstract]

4. Lissau I. Overweight and obesity epidemic among children. Answer from European countries. Int J Obes 2004;28:510-515. [Abstract]

5. Wake M, Salmon L, Waters1 E, Wright M, Hesketh K. Parent-reported health status of overweight and obese Australian primary school children:a cross-sectional population survey. Int J Obes 2002;26:717-724. [Full Textl/ [PDF]

6. Opkin BM. The nutrition transition and obesity in the developing world. J Nutr 2001;131:871-873. [Abstract] / [Full Text] / [PDF]

7. Mohammadpour-Ahranjani B, Rashidi A, Karandish M, Eshraghian MR, Kalantari N. Prevalence of overweight and obesity in adolescent Tehrani students, 2000-2001: an epidemic health problem. Public Health Nutr 2004;7:645-648. [Abstract] / [PDF]

8. Simsek E, Akpinar S, Bahcebasi T, Senses DA, Kocabay K. The prevalence of overweight and obese children aged 6-17 years in the West Black Sea region of Turkey. Int J Clin Pract 2008; 62:1033-1038. |Abstract] / [Full Text / |PDF]

9. Öner N, Vatansever Ü, Sari A, Ekuklu G, Güzel A, Karasalihoglu $\mathrm{S}$, Boris NW.. Prevalence of underweight, overweight and obesity in Turkish adolescents. Swiss Med Wkly 2004; 134:529-533. IFull Text. / IPDF]

10. Turkkahraman D, Bircan I, Tosun O, Saka O. Prevalence and risk factors of obesity in school children in Antalya, Turkey. Saudi Med J 2006;27:1028-1033. |Abstract]

11. Özer BK. Growth reference centiles and secular changes in Turkish children and adolescents. Econ Hum Biol 2007; 5:280-301. |Abstract] / /Full Text. / |PDF ]

12. Cole TJ, Bellizzi MC, Flegal KM, Dietz WH. Establishing a standard definition for child overweight and obesity worldwide: international survey. BMJ 2000;320:1-6. |Abstract] / [Full Text] / |PDF]

13. Katherine M Flegal, Cynthia L Ogden, Rong Wei, Robert L Kuczmarski and Clifford $L$ Johnson. Prevalence of overweight in US children: comparison of US growth charts from the Centers for Disease Control and Prevention with other reference values for body mass index. Am J Clin Nutr 2001;73: 1086-1093. [Abstract] / IFull Text] / IPDF]

14. Kautiainen S, Rimpela A, Vikat A et al. Secular trends in overweight and obesity among Finnish adolescents in 1977 1999. Int J Obes Relat Metab Disord 2002;26:544-552. |Abstract]

15. M-F Rolland-Cachera, K Castetbon1, N Arnault, F Bellisle, M-C Romano, Y Lehingue, M-L Frelut, S Hercberg. Body mass index in 7-9-y-old French children: frequency of obesity, overweight and thinness. Int J Obes Relat Metab Disord 2002;26:1610-1616. [Abstract] / IFull Text. / |PDF]

16. Padez C, Fernandes T, Mourão I, Moreira P, Rosado V. Prevalence of overweight and obesity in 7-9-year-old Portuguese children: trends in body mass index from 1970-2002. Am J Hum Biol 2004;16:670-678. [Abstract| / [PDFI 
Arı Yuca $S$ et al.

Obesity in Eastern Turkey

17. Wang Y, Monteiro C, Popkin BM. Trends of obesity and underweight in older children and adolescents in the United States, Brazil, China, and Russia. Am J Clin Nutr. 2002;75:971-977. [Abstract] / [Full Text] / [PDF]

18. Magarey AM, Daniels LA, Boulton TJ. Prevalence of overweight and obesity in Australian children and adolescents:reassessment of 1985 and 1995 data against new standard international definitions. Med J Aust 2001;174:561. [Full Text]

19. James PT. Obesity: The worldwide epidemic. Clinics in Dermatology 2004;22:276-280. [Abstract] / [Full Text] / [PDF]

20. Mahfouz AA, Abdelmoneim I, Khan MY, Daffalla AA, Diab MM, Al-Gelban KS, Moussa H. Obesity and related behaviors among adolescent school boys in Abha City, Southwestern Saudi Arabia. J Trop Pediatr 2008;54:120-124. [Abstract]

21. Gungor N, Thompson T, Sutton-Tyrrell K, Janosky J, Arslanian S. Early Signs of Cardiovascular Disease inYouth With Obesity and Type 2 Diabetes. Diabetes Care 2005;28:1219-1221. [Abstract] / [Full Text] / [PDF]

22. Must A. Morbidity and mortality associated with elevated body weight in children and adolescents. Am J Clin Nutr 1996;63:445-447. [Abstract] / [PDF]
23. Parsons TJ, Power C, Logan S, Summerbell CD. Childhood predictors of adult obesity: a systematic review. Int $\mathrm{J}$ Obes 1999;23:1-107. [Abstract]

24. Daniels SR, Arnett DK, Eckel RH, Gidding SS, Hayman LL, Kumanyika S, Robinson TN, Scott BJ, St Jeor S, Williams CL. Overweight in children and adolescents: pathophysiology, consequences, prevention, and treatment. Circulation 2005;111:1999-2012. [Abstract]

25. Jolliffe CJ, Janssen I. vascular risks and management of obesity in children and adolescent. Vasc Health Risk Manag 2006;2:171-187. [Abstract] / [Full Text] / [PDF]

26. Freedman DS, Ogden CL, Berenson GS, Horlick M. Body mass index and body fatness in childhood. Curr Opin Clin Nutr Metab Care 2005;8:618-623. [Abstract]

27. Power C, Lake JK, Cole TJ. Measurement and long-term health risks of child and adolescent fatness. Int J Obes Relat Metab Disord 1997;21:507-526. [Abstract]

28. Larrañaga N, Amiano P, Arrizabalaga JJ, Bidaurrazaga J, Gorostiza E. National prevalence of Obesity in 4-18-year-old population in theBasque Country, Spain. Obes Rev 2007;8:281-287. [Abstract] / [Full Text] / [PDF] 